Instituto Internacional de Investigación y Desarrollo Tecnológico Educativo INDTEC, C.A.

DOI: https://doi.org/10.29394/scientific.issn.2542-2987.2016.1.1.15.267-276

OAI-PMH: http://www.indteca.com/ojs/index.php/Revista Scientific/oai

\title{
Gerencia Académica de la Pedagogía del Amor
}

Autora: Mariela Eduvigis Jiménez Campos Universidad Fermín Toro, UFT

mijmenez@ucla.edu.ve

Lara, Venezuela

\section{Resumen}

El presente ensayo tiene como propósito reflexionar sobre la gerencia académica de la pedagogía del amor, a partir de una revisión de los aspectos teóricos constitutivos señalados por Pérez Esclarín (2014) y otros estudiosos que develan al amor como principio esencial de la educación. De allí que, ningún método, técnica o currículo podrá reemplazar las relaciones positivas en educación basadas en el amor, las cuales pueden promover la praxis formativa en el aula de clases generando confianza y seguridad en todos los actores estudiantiles.

Palabras clave: estudiante universitario; gerencia; praxis académica; pedagogía del amor. 


\title{
Academic Management of the Pedagogy of Love
}

\begin{abstract}
This essay aims to reflect the academic management of pedagogy of love from a review of the theoretical aspects according to Perez Esclarín's statements (2014) among others, which reveal that love is the essential education principle. So, any method, technique or curriculum will not replace the positive education relationships based in love, since they can promote the educational practice in the classroom building trust and confidence in all students.
\end{abstract}

Keywords: undergrade student; management; educational practice; pedagogy of love. 


\section{Introducción}

El siglo XXI trae consigo una gran cantidad de transformaciones en muchas esferas de la vida social, educativa, tecnológica, cultural, espiritual, científica y familiar. Estas transformaciones tocan de modo particular el ámbito educativo, con reformas en sus modelos tradicionales por otros contemporáneos.

En este sentido, Delors (1996) en el informe a la UNESCO de la Comisión Internacional sobre la Educación para el Siglo XXI, indica que "la educación tiene la misión de permitir a todos sin excepción hacer fructificar todos sus talentos y todas sus capacidades de creación, esto implica que cada uno pueda responsabilizarse de sí mismo y realizar su proyecto personal" (pág. 12). Este compendio presenta a la educación como aquella capaz de empoderar a los estudiantes a ejercer la gerencia académica y desarrollar sus competencias profesionales, las cuales les permitan desplegar la creatividad e innovación al responsabilizarse por sus acciones como ciudadanos comprometidos de una manera proactiva con la sociedad.

Por consiguiente, la formación del talento humano estudiantil, requiere de la conformación de conocimientos, habilidades, destrezas y actitudes que coadyuven de manera positiva en la dinámica de sus contextos socioculturales, sobre una base curricular eficiente, efectiva y eficaz, permitiendo la consolidación de los conocimientos tecno-científico-humanísticos; así como de un docente comprometido con la gerencia del quehacer académico.

El docente como gerente de aula en la praxis académica debe estar inmerso en una formación permanente e integral, para convertir su gestión didáctica en un quehacer pedagógico que motive, promueva cambios e inspire a los estudiantes a ser cada día mejores en lo personal, académico, social y profesional. Al respecto un docente, según Ramírez (2009) debe ser promotor de una educación para todos, no dirigida a una minoría; de una educación construida a partir de lo mediato e inmediato. De allí puede decirse que una 
educación pensada en el futuro, en un mundo globalizado, no solo contribuirá al saber sino también a la vida.

Atendiendo a estas aseveraciones, como docentes universitarios debemos ser testimonio de vida para nuestros estudiantes, con orientaciones y alocuciones coherentes, porque educamos no tanto por el discurso, sino por lo que somos y hacemos. Por esta razón, debemos plantar semillas y a la vez ser reflejo de actitudes proactivas. La sociedad actual pide con urgencia educadores inspiradores que influyan positivamente en las futuras generaciones, por lo tanto, surge esta interrogante ¿Será necesario reflexionar acerca de las implicaciones de educar mediante una pedagogía del amor, como aquella capaz de dejar una huella imborrable en nuestros estudiantes?

\section{Desarrollo del Constructo Teórico}

A partir de esta naturaleza axiológica, se vuelve significativo desarrollar la noción del amor y la promoción de una educación universitaria sustentada en este sentimiento, abrigando la esperanza de la formación integral signada por la condición humana de vivir con otros, lo que señala Xirau (citado en Barba, 2002), "Educar es en esencia amar".

Desde esta perspectiva, para ser docentes inspiradores, formadores, fieles a nuestros principios y ética profesional, las acciones desarrolladas en el ámbito académico deben ser un ejemplo de amor, paz, armonía, cooperación, solidaridad, compañerismo, tolerancia, sensibilidad, responsabilidad, puntualidad y alegría. Esta visión se despliega en la concepción de Maturana (1999), cuando se refiere al amor como la emoción responsable de organizar la influencia de las acciones humanas, debido a que permite conformar un espacio para desarrollar las interacciones sociales que garanticen la convivencia.

Bajo esta óptica, la noción axiológica del quehacer educativo desarrolla la aceptación de sí mismo y conforma la concepción de otredad en las 
diferentes manifestaciones expresadas en la vida familiar, profesional y ciudadana. En efecto, la acción educativa del docente implica vivir el servicio con alegría, de tal manera que la educación en cualquiera de sus niveles y/o modalidades sea un reencuentro atractivo, placentero, donde se fortalezca la iniciativa, la motivación y se convierta en una aventura, permitiendo experiencias humanas extraordinarias y un aprendizaje significativo.

Esto se evidencia en uno de los resultados obtenidos de la Consulta Nacional por la Calidad Educativa (2014), proyecto realizado por el Gobierno Bolivariano de Venezuela junto al Ministerio del Poder Popular para la Educación, los cuales demuestran que los estudiantes desean un aprendizaje desarrollado en un ambiente positivo de respeto y consideración, donde las horas de clases sean de descubrimiento sobre el sentido de la vida, de estímulo a la curiosidad, de comprensión de los problemas y desafíos de la realidad local y global de manera sencilla pero sin perder profundidad.

Para ello, es necesario realizar procesos introspectivos conducentes a reflexionar y determinar cómo ejercemos nuestra labor docente. No podemos acompañar a los estudiantes más lejos de donde nosotros hemos llegado. Nadie puede exigir si no da, nadie puede dar si no tiene. En este sentido, la pedagogía del amor de acuerdo a Pérez (2014), devela que en la praxis académica "amor" involucra ayuda, apoyo, ánimo, alegría, acompañamiento, amistad. Igualmente, significa afirmar en el estudiante su valía y dignidad, más allá de simpatías, del interés e inteligencia demostrada durante su aprendizaje y aceptarlo como es, distinto a mí y a los demás alumnos.

Por esta razón, los docentes debemos movernos de nuestra zona de confort aceptando los desafíos educativos que implican cambios en nuestra mentalidad y actuación pedagógica, transformando nuestra praxis para convertirnos en docentes inmersos en la pedagogía del amor. Este sentimiento es el valor que en la praxis académica genera confianza y seguridad en todos los actores estudiantiles. Un docente quien ame el quehacer educativo 
universitario, respeta los ritmos y modos de aprender de cada estudiante, inspira sueños y sonrisas, exalta lo mejor, potencia talentos, reconoce la capacidad de comprender y tolerar, aprende junto a sus estudiantes a enfrentar la adversidad, las derrotas, los fracasos; así como aprende de los aciertos y éxitos.

Estos señalamientos nos pueden llevar a promover en la interacción académica la afectividad, alegría, espiritualidad, tolerancia, motivación; además de planificar, organizar y desarrollar de forma consciente e intencionada el proceso educativo con estrategias dirigidas a todas las esferas de la personalidad de los estudiantes. De esta manera, lograr una formación integral que aporte a la sociedad ciudadanos felices, amorosos, solidarios; en otras palabras, formar ciudadanos democráticos capaces de resaltar los principios constitucionales venezolanos del amor, la paz, la igualdad, la equidad y la libertad.

Por eso, todo docente universitario debe tomarse el tiempo para desarrollar una praxis académica integral con perseverancia, esfuerzo, paciencia, amor y mucha fe en sus acciones orientadas a ayudar a los estudiantes a formar su personalidad y carácter como hombres y mujeres de bien, además de profesionales. En este contexto, es importante destacar las afirmaciones de Freire (1989) al señalar que el docente humanista debe tener una profunda fe en el hombre y en su poder creador capaz de transformar la realidad en la cual se encuentra inmerso. Por consiguiente, educar no es un simple acto de enseñar, es una circunstancia educativa impregnada de amor y respeto mutuo.

Por ende, la educación universitaria contemporánea no debe limitarse únicamente a formar conocimientos sino enfocarse en la formación del ser humano integral; una formación dirigida a promover el desarrollo bio-psicosocio-cultural del estudiante que le permita asumir el ámbito social y laboral 
con el talante emocional e intelectual apropiado, el cual adquirirá en sus cimientos el saber, la ética y la moral del modelaje del docente.

En tal sentido, Maturana (1999) considera a la educación como un proceso de transformación donde el estudiante transmuta, consciente 0 inconscientemente, en convivencia con sus profesores y compañeros del entorno universitario. En definitiva, la transformación es el resultado de la interacción del aprender en coherencia con el emocionar, es decir del ser y del hacer.

Desde esta dirección, la gerencia de aula constituye los motivos que llevan al docente a ejercer su labor, por cuanto si un docente realmente ama su profesión, disfruta compartir e interactuar con sus estudiantes. Por su parte, Ruiz (1992) define la gerencia de aula como "la previsión y procedimientos necesarios para establecer y mantener un ambiente en el cual la instrucción y el aprendizaje puedan suceder". (pág. 8). Por lo tanto, la praxis académica cotidiana y la gerencia de aula definen los roles del docente universitario como formador, mediador, motivador, evaluador, investigador, usuario y creador de recursos.

El docente como: (a) formador, promueve el aprendizaje, el desarrollo de competencias básicas, los valores, la autonomía, el estímulo de seguir aprendiendo a lo largo de toda la vida; (b) mediador, enseña a ordenar, procesar y convertir la información recibida en conocimiento; (c) motivador, estimula a sus estudiantes a la utilización de estrategias y herramientas de aprendizaje conducentes a cumplir sus expectativas y objetivos; (d) evaluador, no solo evalúa a los estudiantes, sino también la práctica pedagógica en cuanto a estrategias didácticas; (e) investigador, indaga, diagnostica y soluciona diferentes problemáticas educativas y (f) creador y usuario de recursos, elabora y utiliza los recursos para la ejecución didáctica.

Todos estos roles no deben llevarse a cabo sin una Pedagogía del Amor. Es esencial una educación, la cual además de ser efectiva, haga énfasis 
en la afectividad, la calidad no es posible sin calidez humana. Ningún método, técnica o currículo puede reemplazar al amor, ni al desempeño de un docente universitario que apoye, anime, aliente la alegría y el asombro de descubrir las potencialidades de cada estudiante. La pedagogía del amor se fortalece a través del reconocimiento a las diferencias, de la capacidad de comprender y tolerar, de la posibilidad de dialogar y llegar a acuerdos dirigidos a enfrentar las problemáticas cotidianas y aprender en las dificultades, superando con éxito las limitaciones.

En esta dinámica de relaciones académicas positivas, el docente universitario, se humaniza sin perder su condición de formador exigente, comprometido, responsable, con rigor científico, capaz de cumplir su trabajo sistemático, con dedicación y esfuerzo. En consecuencia, la pedagogía del amor no promueve el dejar hacer o deja pasar, ni el caos, o la indisciplina; por el contrario, promueve la construcción de acuerdos de convivencia, sustentados en el convencimiento del rol transformador del docente y el talento humano que tienen sus estudiantes.

\section{Reflexiones Conclusivas}

El docente universitario que "ama" su rol mediador, cree que cada estudiante es como un "diamante" escondido en varias capaz del "carbón" de su inmadurez, del propio desconocimiento de sus potencialidades intelectuales, creativas y cognoscitivas. Debido a su condición humana basada en el "amor", el docente comprende las individualidades y celebra los éxitos de cada uno de sus estudiantes; está dispuesto a apoyarlos a llegar tan lejos como les sea posible en su crecimiento y desarrollo integral.

De lo señalado, se asume que en la gerencia académica de la pedagogía del amor, educar es un acto de amor mutuo. La pedagogía del amor en la educación universitaria representa para un docente convertirse en mediador con profunda condición humana, al ejecutar su rol de potenciador de 
una formación profesional ejercido con responsabilidad educativa, cuyo propósito insoslayable es educar ciudadanos libres, justos, democráticos comprometidos con el desarrollo de su país.

Finalmente, la pedagogía del amor se aboca a aceptar la conflictividad humana como algo natural asumido a través del diálogo, la promoción del respeto y la tolerancia de las diferencias que permitan resolver los conflictos del modo más eficaz posible, es decir, de manera serena y reflexiva, utilizando siempre el intercambio comunicativo con argumentos racionales y sustentables para encontrar el consenso en pro de una educación universitaria de calidad.

\section{Referencias}

Barba, L. (2002). Pedagogía y Relación Educativa. México: UNAM. Plaza y Valdés.

Freire, P. (1989). La educación como práctica de la libertad. Madrid: Siglo $\mathrm{XXI}$.

Maturana, H. (1999). Emociones y Lenguaje en Educación y Política. Chile: Dolmen.

Pérez, A. (2014). Pedagogía del amor. [Documento en Línea]. Recuperado de: http://antonioperezesclarin.com/2014/11/02/pedagogia-del-amor/

Ramírez, L. (2009). Reflexiones sobre la deserción y la mortalidad estudiantil en las universidades colombianas. Educación y educadores, nro. 5. [Revista en línea]. Recuperado de:

http://educacionyeducadores.Unisabana.edu.co/index.php/eye/article/ view/509/1596

Ruiz, L. (1992). Gerencia en el Aula. Venezuela: FEDUPEL. 


\section{Mariela Eduvigis Jiménez Campos \\ e-mail: mjimenez@ucla.edu.ve}

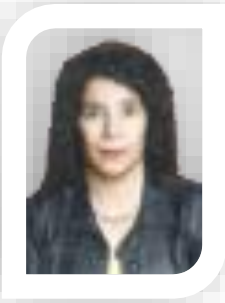

Nacida en Barquisimeto, Estado Lara-Venezuela, el 08 de octubre de 1967. Profesora de Lenguas Extranjeras, mención: Inglés, Universidad Pedagógica Experimental Libertador, UPEL-IPB (1992). Maestría en la Enseñanza del Inglés como Lengua Extranjera, UPEL-IPB (2003). Doctorante en Ciencias de la Educación en la Universidad Fermín Toro (UFT) de Cabudare, Estado Lara. Profesora de Inglés en el Colegio Inmaculada Concepción de Barquisimeto (1992-2003), Docente de Inglés en la academia Piccadilly English Center, Grupo Aeronáutico Lara y en empresas como: Cargill de Venezuela, BOC Gases, Procter \& Gamble. Docente de pregrado y postgrado en UCLA, UPEL-IPB, UPTAEB, UNEXPO. Profesora ordinaria a tiempo completo de pregrado en el Decanato de Ciencias y Tecnología (DCyT) UCLA y de postgrado en los Decanatos de Veterinaria y Agronomía de la UCLA, desde el 2003 hasta la fecha. Actualmente, Coordinadora de Cultura del DCyT-UCLA, Coordinadora del Área de inglés del DCyT-UCLA, Miembro del Consejo de Investigación del DCyT-UCLA. Así como, Jurado de trabajos de investigación, ponente y coautora de libros para la enseñanza del inglés, titulados: "TIME OFF 1", "TIME OFF 2" y "TIME OFF $3 "$.

El contenido de este manuscrito se difunde bajo una Licencia de Creative Commons ReconocimientoNoComercial-Compartirlgual 4.0 Internacional 